\title{
Tv World as a Simulation of the Real World in the Game "Persona 4"
}

\author{
Richard Lawrence \\ English Department, Faculty of Letters, Petra Christian University \\ Surabaya, East Java, Indonesia \\ e-mail: chazzprinceton867@gmail.com
}

\begin{abstract}
Throughout the years RPG games have developed so much to such a way that it is not only a media for playing, but also a media for telling interesting stories based on characters' interactions. In this study, I observe the process of simulation in the game Persona 4 and how it affects the characters and the over world. With the assumption that the TV world is paralleled to the real one in the sense that they reflect each other and that the characters in the TV world unmask the personalities of the characters in the real world in the way that the TV world version is the representation of the real version's desire, I would like to analyze the way the TV world acts as an imitation to the real world and how the characters from the TV world unmask the personality of the characters in the real world. In analyzing the game, I use the theory of simulation and simulacra which was proposed by Jean Baudrillard. In gathering the materials, I play the game and also watch videos of people playing the game in order to get footage and story context which will later be used as proofs. In the analysis I find that social interaction is the main element that makes the TV world parallel to the real world. The parallelism between the TV world and the real world can be seen trough the encounter between the characters from the real world and their counterpart from the TV world.
\end{abstract}

Key words: Shadow, TV world, Counterpart, Real world, Protagonist, Simulation

\section{INTRODUCTION}

RPG or Role-Playing Game is one of many genres in video game. In this type of game, players assume the role of a specific character and go on an adventure in a fictional setting. I decided to write about RPG game because RPG games are more than just a game. In RPG I find that the concept of a story-based game is really powerful in attracting people's interest, because it is easier for the players to feel connected through several aspects of the RPG games. In RPG games players are responsible in deciding how the main characters they play will develop. As the story progresses, the main characters will undergo changes that will affect their character traits.

Before the formula that the RPG games now use, the history of RPG goes back to 1970s on mainframe computers. The first RPG game was inspired by pen and paper game called Dungeons and Dragons. According to Greg Porter, in an online article entitled "Where we've been and where we're going" role-playing game's history is classified by the features they implement from one generation to generation. In his research he mentioned that there were several generations of RPG in which he mentions "Free-form, rule-less role-playing" (Greg Porter, 1995). There are no formalized systems, no good way to arbitrate disputes. It also includes any incidental role-playing that is used for strategic or entertainment value in other games, such as playing a general in H.G.Wells' Little Wars, etc." he also mentioned that this form of RPG was the "Generation 0" RPG that was going on in the last sixties. The significant development of RPG games from Generation 1 and the next ones has triggered games developers to introduce cool features with the purpose of giving new experience to RPG. One of the known creative developers in RPG game is Okada Kouji. Since 1983 Okada Kouji, also known as Cozy Okada has become the creator of Shin Megami Tensei game series.

The significant development of RPG games from Generation 1 and the next ones has triggered games developers to introduce cool features with the purpose of giving new experience to RPG. One of the known creative developers in RPG game is Okada Kouji. Since 1983 Okada Kouji, also known as Cozy Okada has become the creator of Shin Megami Tensei game series. Mentioned in wikipedia.org, 
his works have become well known by so many people mainly through the game Devil Survivor and the Persona franchise. Prior to its popularity in the west, the game, Persona 4 was a major franchise in Japan, having sold over 4 million units by 2008. By November 2014, the series has sold approximately 13 million packaged units worldwide, with the combined series grouped within the Megami Tensei franchise accounting for 7 million and the Persona series accounting for 6.2 million. The narrative of the game above informs me that the TV characters are actually a simulation of the people who appear in the real world of the Persona 4 game. Throughout the story I find out that even though they look similar at the beginning, the real world characters are actually very different from their TV characters.

Okada Kouji's Persona 4 begins when the main character arrives in the town of Inaba to live with his uncle for one year. While he lives in that town there are several unexplained murder cases. After a couple of days living there he heard rumors about midnight channel. In the rumors, people say that it shows the people who are going to die. In the rumors that he heard, the midnight channel will only appear on rainy night. Because he is curious, the protagonist tries to wait for it in his room, in front of a TV. When the clock hits 00.00 , the TV suddenly turned on while showing only noisy image of a girl. While looking at the TV he feels like someone is calling him from inside the TV. He then tries to put his hand on the screen. His hand suddenly sucked into the TV, but he is able to get it out. After discovering this ability the protagonist and his friends try to use it on bigger TV so that the protagonist can enter his full body to the TV. After the protagonist gets sucked into the TV with his two friends, they meet a doll like creature named Teddie, and he reveals that they are in another world. This world inside the TV will then be called the TV world by the protagonist. After the protagonist discovers the TV world, it turns out that the source of the unexplained murder cases is the creatures inside it.

The narrative of the game above informs me that the TV characters are actually a simulation of the people who appear in the real world of the Persona 4 game. Throughout the story I find out that even though they look similar at the beginning, the real world characters are actually very different from their TV characters. Yukiko being the example, though it is true that the real one and the shadow one share a similar desire to escape their lives as an inn manager, the real Yukiko has only reveals that idea after the shadow introduces the idea to her. In the end, when Yukiko's Arcana reaches level 10, the protagonist also finds out that she does want to take care of the inn and the thought of escaping is just a temporary idea.

In order to answer the question I have in the statement of the problem, I will use the theory of Simulation and Simulacra from Jean Baudrillard as the main theory. This paragraph will mainly focus in explaining the theory of simulation and simulacra. Simulations and Simulacra as explained by Baudrillard are created to analyze the relation between reality, symbol, and society. In his theory he explains that Simulation means a copy of reality with slightly altered feature like for example in a movie where they show a city in India. The city in that movie is a simulation based on a real city that really exists in the real world like Bombay, so they will show a house or some buildings which can be identified as a Bombay special. However, there is also one more key word in her books which is called Simulacra. Unlike simulation, simulacra are merely a copy without an original. One example is Disneyland, when someone goes there they will see something familiar like castle of a princess or a house for Mickey Mouse, but those things does not exist out of the Disneyland in the first place so it is called a simulacra because people may consider it a copy of something but that something when actually it has no original form.

In explaining the simulation that happens in the game I will use the four stages of simulation proposed by Jean Baudrillard. The four stages of simulation can be considered as steps for simulation to take over reality. The explanation of the four stages itself is as follows. The first stage is explained as "the reflection of a profound reality" (Jean Baudrillard, 1981, p. 6). In this stage "reflection" is meant to be an exact copy or having the same look with what is real thus deceiving those who see it and consider it as "reality". The second stage of simulation "masks and denatures a profound reality" (Jean Baudrillard, 1981, p. 6). In this stage, the sign which at first stage shows an exact copy of the real, in the second stage the signs "denatures" the signs or alter its quality. The third stage is where the "real" starts to fade away. Budrillard explains that in the third stage "it masks the absence of profound reality" (Jean 
Baudrillard, 1981, p. 6). The "absence" in Baudreillard's explanation means that the signs eventually create a gap between people and the real. Thus, believing more on the simulation which in the second stage have been altered from what is essentially and exact copy. In the fourth stage, it is mentioned by Baudrillard as "pure simulacrum" (Jean Baudrillard, 1981, p. 6). In this stage what is not real or the simulation has become what is believed to be real.

\section{Real world Versus TV world}

In explaining the simulation that happens in Persona 4, I am going to use the aspects of society and communication. Society and communication are important part on describing a world, a place, or just a small group because they are able to show how the people in that world, place, or group are interacting with each other by the way they communicate with each other.

\section{Society and communication}

One of the aspects of the TV and real world that I am going to analyze in this sub chapter is how society works in those two worlds is how society works. Society is defined as "people in general thought of as living together in organized communities with shared laws, traditions, and values" (oxford dictionary online). The Sage Dictionary of Sociology explains further that society as group of people is characterized by a "distinctive culture and set of social institutions" (Bruce and Yearly, 2006. p286). The social institutions in the real world and the TV world of the game Persona 4 are reflected by groups of people who have different backgrounds such as police officers, shop owners, and students in school.

In Persona 4, Kanji Tatsumi, a character in the TV world is able to materialize his dark desire although he is a good guy. This happens because of the absence of society in the TV world. Kanji's homosexual tendencies will not pose a problem in the TV world. The fact that Kanji is a homosexual is not a problem. This is different from the situation in the real world where there are some segments of the society that cannot accept homosexuality. So, there is a potential friction between, for example, Kanji Tatsumi and those who condemn homosexuality. Jean Jaques Rosseu, a political philosopher once mention in his book about social contract theory. In social contract theory he explains that people must surrender some of their freedom while living among others in one place which he refers to as social contract. Kanji did not flaunt his homosexuality in the real world. Kanji has to accept the fact that people disapprove of homosexuality. In that case, if Kanji insists on flaunting his homosexuality then chaos will be unavoidable. What I mean by chaos is how the emergence of civilizations may give people a reason to fight with each other, like fighting for who is stronger or who is better at studying.

Kanji's case can be used in explaining the connection between the real world and the TV world. If he is a gay in the TV world, he cannot goes out to the society because the idea of someone being homosexual is not a popular belief. In answering this question I would like to use the four stages of simulations proposed by JeanBaudrilard. As explained before, in the TV world there lives a character which is the same as the character in real life which is called "shadow." This shadow, acts as the first stage of simulation, which is trying to mimic reality or becoming an exact copy. When I Look at this context, I find out that the shadow version of the character is trying to mimic the character in real life by showing a similarity so that he/she is believable by others, just like we often see in movies.

Aside from group of people, another aspect of a society is communications. Like what mentioned above people in society must communicate in order to understand one another. This process is done through the use of language like we all know. Unlike group of people, communication is an aspect that can be found in both the real world and the TV world. Language is used as a means of communication among human beings, and as civilization developed language is not used for communications only. In his book, Philosophical Investigation Ludwig Wittgenstein mentions that language is used not only for communication or transmitting one idea from one person to another, but also for a tool to carry out so many things like lying, deceiving, and comforting people.

The repetitive dialogues prove that they are unable to use different variations of communications or using the language in different ways. That being said, the TV world characters only appear as a part of simulations to their real world counterpart. In this part, it starts entering the second stage of simulations where the simulation starts to show that it is different from the original by showing differences. 
Entering the first stage of simulation, the TV world shows how similar it is to the real world. This is achieved by showing the same look of the character in real world. Later it starts to show some differences such as, how the TV characters do not have social life and how limited is variant ways of using language. The observation that shows that the society in the real world and the TV world are different only reflects two stages of simulation which will later be able to be expended by the conversations and interactions of the characters.

\section{Rules and Regulation}

After investigating the society of the game in both the real world and the TV world, in this section I will focus on investigating the rules and regulations found in the worlds of the game. In Persona 4 , the real world is full of rules and regulations. Regulation is defined as "a rule or directive made and maintained by an authority" (oxforddictionary.com). Based on that definition I want to show how a higher positioned person or group established directives that others below them must obey, or why a certain action can or cannot be done. Whereas, the meaning of rule is "one of a set of explicit or understood regulations or principles governing conduct or procedure within a particular area of activity." (Oxforddictionaries.com) Similar to regulations, rules are basically a regulation in smaller scales which are often used in smaller situations like in a game, or classroom instead of a bigger one like regulations which are often used in larger scale like one society or a workplace.

At a first glance the connection between the real world and the TV world is almost non-existent. However, furthermore, the game I find out that the TV world is actually a form of simulation of the real world in terms of rules and regulations. The first stage of simulation can be seen at the beginning of the game. In the beginning there is a time when the protagonist is confronted by the police like the example below.

At this point of the game (figure 16), the protagonist has only gone to the TV world once and meets Yosuke's shadow. The scene above is taken right after the encounter of the first shadow. At this part of the game I can say that this is the first stage of simulation because by the time the protagonist encounters more shadows of other characters, the protagonist never finds himself restricted by rules like the part in the picture above (figure 16). Later on the second stage of simulations appears in the form of law breaking. After entering the TV world for several times, the real world does not show law enforcement (arrows in figure 16) like how the protagonist was captured in the previous examples. The protagonist and the other characters however develop a rather law breaking attitude like the example below. This particular part of the story is the second stage of simulation because unlike the previous part of the story, the protagonist just recklessly tries to inflict his own justice to other people. In another example below, the person that they attack also mention about the rights of ordinary citizen which give us the idea of how the law works in this particular part of the real world. Looking at those facts it clearly means that the protagonist and the other characters are clearly affected by the fact that they have experience a lawless place thus unmasks their animalistic desire to just attack. Those facts prove the process of the second stage of simulations. The sign becomes the "prevention of reality" (Jean Baudrillard, 1981, p6). That they have been living in for years means that people can no longer see clearly what is real.

The third stage of simulation is "the absence of profound reality" (Jean Baudrillard, 1981, p6). At this point simulation is finally believed to be a part of reality. However, in this aspect of the game, the third stage of simulation does not occur. This happens because the third stage of simulations does not take part in rules and regulations. The protagonist and the other characters do not show any more action of breaking the law or using the lawless rule of the TV world in the real world. Instead, the game goes directly to the fourth stage, as shown by one character named Tohru Adachi.

In the game, in the four stage of simulation, Adachi is seen as an amateur detective who always goofs off every now and then at his work time. However, at the end of the story the character of Adachi becomes one of the final antagonists. Adachi later reveals in his dialogue that the real world is not needed, thus, making him a perfect example for the fourth stage of simulation where people can no longer differentiate which one is real and which one is not.

\section{The TV world characters VS the real world characters}


In this sub-chapter, I will use the characteristics of the characters in the game in order to prove the simulation that happens between the real world and the TV world. I use the characteristic of the characters because the transformation of beliefs between what is real and what becomes the real are mostly shown by the characters and how their characteristic change, after they succumb to simulation.

\section{The TV world characters VS the real world characters}

In this sub-chapter, I will use the characteristics of the characters in the game in order to prove the simulation that happens between the real world and the TV world. I use the characteristic of the characters because the transformation of beliefs between what is real and what becomes the real are mostly shown by the characters and how their characteristic change, after they succumb to simulation.

Looking at the dialogue, I found out that the real world Yukiko starts to get affected by the words that the shadow Yukiko says about her personality and desire. This is a proof that shows how the second stage of simulation is in progress. The evidence of this being the second stage is the shadows adds another characteristic in what is supposedly the characteristic that Yukiko understands to be herself, which is the unwillingness to inherit the inn. Another example of this stage is Kanji's dialogue with his shadow.

Another example that shows that a character is still in the first stage of simulation is Yukiko's case. In one conversation, it seems that Yukiko starts to believe what the Shadow Yukiko says about her, although, she ends it by saying "no! You're not me!" the fact that she screamed shows that actually that she believes that it is true but she cannot accept that fact. Kanji, on the other hand, does not show any signs of believing the shadow Kanji. However, near the end of the dialogue, Kanji does believe that the one he sees in front of him wearing his face is actually he himself; and his statement about Kanji is true. Kanji's statement "No... nuh-uh! No way!" shows that he is nervous about it because he thinks that it is true. At the end of the dialogue, Yukiko calls "Kanji-kun." Yukiko's call shows that she actually believes that the Shadow Kanji is in fact the actual Kanji. This incident shows that Kanji's position is in the first stage of simulation because, by this point, it is the first time he encounters his shadow. Yukiko, however, has met the shadow once before. That is why she has already entered the second stage of simulation when this conversation starts.

Another example of the third stage of simulation comes from Yukiko and Kanji. Yukiko and Kanji's dialogues are the third stage of simulation because the shadow starts talking as if they are the real world characters. Thus making it an "absence of profound reality" (Jean Baudrillard, 1981, p. 6). As mentioned by Baudrillard. It is later shown through the dialogue between Shadow kanji and the other characters. Just like Yukiko's case, this dialogue shows how the conversation between Kanji and his TV world version is a form of the third stage of simulation.

\section{Power Dominance}

The next aspect that I want to discuss is power dominance. This power dominance exposes how the characters from the TV world try to take over the characters from the real world. So, power dominance will serve as a tool to understand the process of simulation. Seen from this perspective, the characters in the TV world are able to dominate the characters in the real world in one way or another. Thus, the power dominance could explain the efforts of the characters from the TV world to dominate their real world counterpart. Power is defined as "the ability or capacity to do something or act in a particular way", and dominance means "power and influence over others" (oxforddictionaries.com). The two definitions above provide platform to analyze the character of Rise Kujukawa and Naoto Shirogane.

From the example above I see that the TV version of Rise is trying to push the desire of showing her true self to the public to the real world version of Rise. This scene gives context to Rise's character because, just like explained before, Rise is an idol which makes her acting a lot, meaning that the public only knows her as the idol persona instead of her real self. This part is considered as the first stage because the other characters start to see this TV world character as Rise or at least as somebody whom they know in the real world. Another example is the dialogue when the protagonist meets Naoto's shadow for the first time.

The second stage of simulation for this topic happens before the protagonist fights the TV world characters. This part of the game is considered as the second stage of simulation for some reasons. The first reason is that the protagonist and the other characters are finally able to witness that the TV world 
version and the real world version of the characters are two different people. However, the characters are still treating the TV world version and the real world version as one. Secondly, the TV world characters keep on imposing their personality to the real world characters and the real world characters start to believe them because they have the same face. The example below will give proofs of how this part of the game is considered as the second stage of simulation.

The next one is the third stage of simulation. To explain how the third stage of the simulation, I will be using the example from the game in which the characters have finally defeated the TV world characters. Just like the explanation of the third stage of simulation it is described by Baudrillard as "order of sorcery" (Simulacra and Simulation, 1981) that Sorcery is often connected with magic and is able to manipulate a person. The third order of simulation just like described before is a stage where the signs mask the reality. The example below will give proofs of how the reality is masked by signs which take form as the TV world characters.

The last part of this research is the fourth stage of simulation as it happens in the field of power dominance. The example, in this part, will be an explanation about the personality changes of two characters and how they are overpowered by their TV world counterpart.

\section{Conclusion}

This research about the TV world as a simulation to the real world in the game Persona 4 appear to be true based on some answers found in the previous chapters. The research is also able to pinpoint the aspect of the characters as well as the setting which is affected by the simulation that happens in the game.

While looking at the society and communication as well as rules and regulations aspect of the game there are several things that I found regarding the purpose of this research as of how the TV world actually unmasks the personality of the real world characters in Persona 4. The first thing that I found regarding what is said above is in the matter of society in communication. By using the four stages of simulations, I found out that actually the social interactions between the characters in the game are affected by the fact that the characters from the real world met the characters in the TV world.

In the second sub chapter I dealt in more with the characters in them game. In the game I found out that even though we see the changes and effects of the encounters of the characters of both worlds in a big way such as, society, communication, rules, and regulations, also the changes personally from individual characters. Using the four stages of simulation, I found out that the characters of the real world from the game Persona 4 also are affected by their interaction with the TV world. We can see the affect that the real world characters undergo from two ways which are human desire and power dominance.

\section{BIBLIOGRAPHY}

Baudrillard, J., \& Poster, M. (1988). Selected writings. Stanford, CA: Stanford University Press. Baudrillard Short Introduction. (n.d.). Retrieved September 28, 2016, from http://publish.uwo.ca/ dmann/baudrillard1.htm

Bruce, Steve and Yearly, Steven. 2006. The Sage of Dictionary of Sociology. Thousand oaks, CA: Sage Publication Inc

By Thomas Sebeok (Author). (n.d.). Signs: An Introduction to Semiotics Paperback - June 9, 1994. Retrieved September 28, 2016, from https://www.amazon.com/Signs-Introduction-SemioticsThomas-Sebeok/dp/0802077803

Chandran, N. (2007, October 6). Shin Megami Tensei. Retrieved June 27, 2016, from http://web.archive.org/web/20140724122428/http://rpgfan.com/reviews/smt/index.html

Cozy Okada. (n.d.). Retrieved September 28, 2016, from http://megamitensei.wikia.com/wiki/Cozy_Okada

Harrigan, Pat \& Wardrip-Fruin, Noah. (2010). Second Person: Role-playing and Story in Games and Playable Media. MIT Press.

Introduction to Jean Baudrillard, Module on Simulacra and Simulation. (n.d.). Retrieved September 28, 2016, from https://www.cla.purdue.edu/english/theory/postmodernism/modules/baudrillard 
Kim, J. (2008, July 29). "Narrative" or "Tabletop" RPGs. Retrieved June 27, 2016, from http://www.darkshire.net/ jhkim/rpg/whatis/tabletop.html

Mann, Doug. "Baudrillard Short Introduction." Baudrillard Short Introduction. N.p., n.d. Web. 04 Jan. 2017.

Modules on Baudrillard II: on simulation. (2002). Retrieved June 27, 2016, from https://www.cla.purdue.edu/english/theory/postmodernism/modules/baudrillardsimulation.html

Porter, Greg. "The Oracle: Essays." The Oracle: Essays. N.p., n.d. Web. 04 Jan. 2017

Riddick, and a \$1.4 Billion Online Industry." Isebrand. N.p., n.d. Web. 04 Jan. 2017.

Rouse, M. (2011). Internet applications glossary : role-playing game (RPG). Retrieved June 27, 2016, from http://whatis.techtarget.com/definition/role-playing- game-RPG

Sebeok, Thomas Albert. "Signs: An Introduction to Semiotics." (1994): 1-187. Web. 4 Jan. 2017.

Simulacra and Simulations. (n.d.). Retrieved September 28, 2016, from http://web.stanford.edu/class/history34q/readings/Baudrillard/Baudrillard_Simulacra.html

Simulacra. Retrieved June 27, 2016, from http://it.stlawu.edu/ global/glossary/simulacra.def.html

Tychsen, A. (2008). Play story: Communication, character and cross-platform gaming experiences in multi-player role playing games. Australia: Macquarie University. The Oracle: Essays. (n.d.). Retrieved September 28, 2016, from https://www.rpg.net/oracle/essays/wherewevebeen.html

Ward, R. K., \& Fernando, J. (n.d.). Theory Beyond the Codes. Retrieved March 18, 2017, from http://www.ctheory.net/articles.aspx?id=685

Wells, Hebert George. "Role-playing Games: From H.G. Wells to D\&D, the Gen X Gamer,

Williams, J. Patrick., Hendricks, Sean Q., Winkler,W. Keith. (2006). Gaming as Culture: Essays on Reality, Identity and Experience in Fantasy Games. McFarland.

Wittgenstein, Ludwig. Philosophical Investigation. Oxford: n.p., 1953. Print. 